\title{
A different planet: Neuromedia asset management
}

\author{
Ben Howell Davis \\ is Principal Consultant, Davis International Associates, a digital asset solutions provider focused on strategic planning for long-term \\ digital continuity. Formerly he was Senior Scientist and Strategic Director for Media and Entertainment, Razorfish, Inc.; Manager of \\ Communications, Getty Information Institute, and Manager, Electronic Publications, Getty Trust Publication Services, Los Angeles. \\ Previously he was a research associate at the Massachusetts Institute of Technology, Manager of the AthenaMuse Software \\ Consortium at the Center for Educational Computing Initiatives (MIT/CECl) and Manager of the Project Athena Visual Computing Group. \\ He was also an instructor at the MIT Media Lab, a Fellow at the MIT Center for Advanced Visual Studies, and a lecturer in the MIT \\ Visual Arts Program. His publications include art and technology reviews for Scientific American Magazine and Time and Bits: \\ Managing Digital Continuity, and When Everything Learns.
}

Keywords: neuroscience, biotechnology, neuromedia, cognitive science, digital continuity, DNA computing, non-silicon computing, molecular memory

\begin{abstract}
Because of the synergy between computational advances, neuroscience, and biological understanding, we can now begin to manipulate living systems on a level with our ability to manipulate physical and chemical systems. This synergy will have a direct effect on our relatively new digital asset technologies. The serious problems of the ephemeral nature of digital records will inevitably be supplanted by technology influenced by the biosciences. A carbon-based solution to storage media might radically change the digital preservation and asset strategies of emulation and/or migration of data. Because this is a revolution in our understanding of the nervous system and its environment, the revolution will work both ways - from culture to science as well as from science to culture - as we incorporate the application of these discoveries back into the creative process and the technologies that support them.
\end{abstract}

Ben Howell Davis Davis International Associates,

1064 Long Cove Road

Port Medway,

Nova Scotia BOJ 2TO,

Canada

Tel: +1 5025217040

Email: bend@ca.inter.net

\section{INTRODUCTION}

Recent experiences in strategic planning for the Graduate Industrial Design Program at the Art

Center College of Design in Pasadena,

California, the LA Freewaves media arts

network, and as a participant with

InterPARES 2 (International Research on

Permanent Authentic Records in Electronic

Systems) have made me aware of an emerging information condition of "neuromedia" that will have important implications for multimedia asset management.

Because of the synergy between computational advances and biological understanding we can now begin to manipulate living systems on a level with our ability to manipulate physical and chemical systems. This synergy will have a direct effect on our relatively new digital technologies. The ephemeral nature of digital records will inevitably be supplanted by technologies influenced by the biosciences. A carbon-based solution to storage media might radically change digital preservation strategies of emulation and/or migration of data.

Because this is a revolution in our understanding of the nervous system and its environment, the revolution will work both ways - from our cultural heritage to science as well as from science to culture heritage - as we incorporate the application of these discoveries back into the creative process and the technologies that support them.

For instance, it was recently announced (February, 2003) at Simon Fraser University ${ }^{1}$ that a single molecule switch has been developed that would enable computers to have 10,000 times as much memory as current computers. This bio-chemical approach to computational design is a good example of how rapidly crossdisciplinary understanding will take effect in new products. In the same month, Intel announced a new chip technology that supercharges cell phones to access the internet, display digital photographs, play music and perform other 
complicated tasks. Cell phones in a sense are becoming communication devices, remote controls, and multimedia displays.

The concept of aligning and managing digital assets is a reaction to the evolution of digital production and multimedia networks. The current understanding of this evolution is rooted in experiences in the library and museum communities, the digital solutions and design disciplines, the communication and entertainment industries, and law. Aligning and managing multimedia assets is predicated on these origins. Neuromedia will have many more levels of assets. One important distinction is that in a neuromedia environment communication between assets is a given. Just as all the biological systems within us and all the biological systems in nature communicate - and there should be a distinction made between communicating and interacting - all the assets created in neuromedia systems will actively exchange and employ information to create new information, not merely react and store reactions. This aspect of neuromedia will radically change the quality and density of multimedia created. In addition to "cross-talk" data, there will need to be attention to assets created and maintained in scientific support systems, in artistic and social support systems, in collaborative science and art production tools, in cross-disciplinary content development, in automated metaphorical dependent taxonomy development, in multiple user destination designs, in science/art audience interactions and communications, a variety of international legal monitoring, and multicultural ethical debate. Programming paradigms may come from areas of current research like pervasive computing, non-silicon-based research into quantum computing, DNA computing, biological computing, molecular memory, and advances in nanotechnology to name just a few.

The confluence of knowledge coming from neuroscience, cognitive science, genetics, psychology, biology, nanotechnology engineering, computing, software development, networks, and advances in the mathematics supporting them is having a powerful impact not only on science but on the humanities, social sciences, design, the performing and fine arts, and the preservation of cultural heritage. This change has been augmented by the application of imaging technologies that are producing a new understanding of the nervous system that is opening up new scientific understanding of human behavior while giving artists and designers a range of tools and modes of conceptualization never known before.

Questions raised by neuromedia will be far reaching. Some examples of current production, archiving, and efforts to establish international standards are relevant as preparation for these questions.

\section{ART CENTER AND CALTECH}

In just two years, the Graduate Industrial Design Program at the Art Center College of Design in Pasadena, California has transformed itself from a traditional industrial design program that would usually be focusing on the creation of furniture, appliances, and architectural components into a new kind of program with courses like "Pretty Inside: Designing for the Interior of the Body" that involves collaboration with the nanotechnology researchers of the Jet Propulsion Laboratory at CalTech. Fashion design students, for instance, were suddenly confronted with deep issues in creating for the human body. Art Center instructor and designer Stacie London creates objects that capture a person's self-image. She generates a custom form developed from a collaborative investigation in the geometry of organic shapes and textures her client finds an identity with. Using rapid prototyping technology, she creates the digital image of the object and the physical realization of the computer file, resulting in a computeraided design/computer-aided manufacturing (CAD/CAM) object. With the

"PERSONALfile" as the underlying form, London generates a suite of personal objects, ranging in size from microscopic to monumental - from cell phones to furniture. This process presents the possibility of creating an identity, based on a 3D object stored as a computer file, which can be updated to match a person's evolving taste and sense of identity. The PERSONALfile serves as both personal object and electronic persona. This approach is in direct response to "growing" an evolving form which is continuously linked to the person using it. It is a bio-computing approach to style. It generates enormous quantities of digital assets that all interact. 


\section{Have you ever wondered how other species see the world?}

Opened in April 2003 at CalTech and Art Center, "NEURO" was an exhibition that exposed the future problems of neuromedia asset management. Six artists were paired with six scientific researchers to create works that push boundaries in both the arts and sciences. Ken Goldberg, a conceptual artist and professor of engineering at UC Berkeley was affected by the events of 11 September, 2001 and wanted to understand how two cultures view the same event completely differently. He began working with Pietro Perona, the director of the CalTech Center for Neuromorphic Systems (The Center for Neuromorphic Systems Engineering at CalTech focuses on sensory systems for robotics) on his "Infiltrate" project that involved using scientific research on how flies see, adapting the research to how fish see, filling a 110-gallon tank with six koi - one orange and five white and using advanced hardware and software and three cameras to track what the orange fish sees, reconstruct it and project in on a wall. Visitors figure out the correlation between movement in the tank and movement on the wall, to get a sense of seeing like an orange koi.

In another piece for NEURO, artist Jessica Brown created "Perpetual Perceptual (about a rose)", which uses lightsticks to emit words categorized by sense - sight, sound, taste, smell, and touch - which describe a rose which is absent from the space. Perpetual Perceptual (about a rose) employs a phenomenon referred to as "retinal painting," whereby viewers are most likely to see an image when they are not looking directly at its source. Retinal painting became the conceptual premise for Bronson's project, playing upon the idea of peripheral vision as well as ways of looking at art. The artist deliberately chose a site within the gallery that is peripheral to the main exhibition space, and also visible to people walking along an exterior glass-walled corridor adjacent to the gallery.

Christian Möller's work CHEESE was an experiment in the architecture of sincerity. Inspired by the omnipresent friendly, smiling faces of Hollywood's entertainment industry this work is based on the research on "emotion recognition" by the Machine Perception Laboratories of the University of California,
San Diego. More than 800 young actresses answered a small ad in an entertainment industry trade magazine: "Looking for actress, news anchor type, for a series of video portraits." CHEESE is a human-computer interaction in which the computer takes the dominant position. On camera, six actresses each try to hold a smile for as long as they can, up to one and a half hours. Each ongoing smile is scrutinized by the computer perception system and whenever the display of happiness falls below a certain threshold, an alarm alerts them to show more sincerity. Displayed in the gallery on six flat panel monitors, sequenced adjacent to each other along the wall, the piece creates a concert of alert signals within an ambience of forced friendliness and irritating melancholy.

\section{LA FREEWAVES}

Multimedia cultural heritage preservation is a dynamic, evolving endeavor. Cumulative cultural repositories for new media, multimedia, and future-media are conditions that provide exceptional test beds. "Cumulative" in this context means that an organization or institution accepts, on an ongoing basis, cutting edge applications of art and technology. The business of the organization is to promote, distribute, display, and archive the latest efforts of artists and social activists to use information technologies for expression.

LA Freewaves is a nonprofit media arts network that produces the largest independent biennial media arts festival in the USA as well as ongoing workshops, curriculum materials, and a website that encourages artistic and social expression. Since 1989, this innovative organization has exhibited dynamic and culturally relevant experimental multimedia from around the world at alternative and established venues throughout Los Angeles by coordinating activities with 65 arts organizations, 68 schools, 74 libraries, 32 cable stations, 35 programmers, and more than 2,000 video makers. LA Freewaves is now contemplating merging with two other alternative media organizations that have satellite access in order to broadcast its festival and archival holdings internationally.

LA Freewaves multimedia archive holds hundreds of hours of video in a variety of 
formats, hundreds of websites, CD-ROMs and DVDs, editions of print catalogs, curriculum guides, festival ephemera like posters, administrative and publicity databases, correspondence, and design materials. Since 1989 the formats have gone from installation video performances to interactive multimedia, to internet, to DVD, to any combination of these formats. With an interest in satellite broadcast as well as evolving forms like those in the NEURO Exhibition, LA Freewaves continues to keep pace with expanding definitions of new media. The development of the archive is itself a kind of work of art that will survive as an example of how multimedia has evolved.

What confronts LA Freewaves now is not how to get access to the latest, most innovative uses of multimedia, but how to establish a sustainable mechanism that can cope with the acceleration of changes in multimedia while creating an effective strategy for preserving its acquisitions. The cumulative multimedia inventory that LA Freewaves represents must keep pace with artists, must preserve its inventory, find new ways to expose its inventory, and must deal with increasingly complex, next-generation technologies because artists are always at the leading edge of cultural experimentation.

\section{INTERPARES 2}

There are a variety of projects attempting to deal with the issues of preserving electronic records. As Manager of Communications for the Getty Information Institute, I interacted with many of them including a Getty-sponsored meeting in 1998 called Time and Bits: Managing Digital Continuity which brought a number of interesting minds together (Stewart Brand, Danny Hillis, Brian Eno, Brewster Kaele, Kevin Kelly, Jaron Lanier, Doug Carlston, and others) to try to unravel the issues of preserving electronic records. The conclusions of the meeting were startling at the time. Everyone using digital technology assumed that someone else — industry, the government — was taking care of preservation. The reality was that, although it was discussed academically, no one seemed to be doing it. The fear was that the turn of the century would be seen historically as a dark time when a great deal of electronic information would be lost because the media used to record it would not last more than 25 years at best. Since that time the Library of Congress and others have taken up the issues in regard to the current ephemeral nature of digital materials. Strategies for migration, emulation, and the archiving of hardware as well as software seem to have the problems at bay.

As an arts researcher and participant in InterPARES 2 (International Research on Permanent Authentic Records in Electronic Systems, www.interpares.org) I have become aware of a host of new issues. Launched at the University of British Columbia's School of Library, Archival and Information Studies from April 1994 to March 1997, InterPARES 1 defined the requirements for creating, handling, and preserving reliable and authentic alphanumeric active electronic records. InterPARES 2 is a multidisciplinary international collaboration that is applying a multi-method approach to the development of concepts, processes, and tools that will help in the securing of a protected and lasting environment for the digital records produced in interactive, dynamic, and experiential systems in the course of artistic, scientific, and electronic government activities.

What has become apparent after attending a recent workshop meeting in Vancouver is that the long-term issues of "authentic" multimedia records is vastly more complex than the current efforts to define models for preservation. The definition of multimedia is headed for neuromedia. This condition will produce an environmental approach to records management, an ecological model that will be much closer to modeling the nervous system than current modes of data modeling. One of the most revealing areas where this becomes apparent is legal evidentiary requirements. The network of interconnected legal areas include: social access in terms of freedom of information legislation, privacy legislation, intellectual property like copyrights, patents, trademarks, technological control (longevity), expression including freedom of speech, press, conscience, and security; processes like the Paperwork Reduction Act, e-government commerce regulations, ISO 900, records retention, licensing; technical standards like ISO, digital signatures, digital rights management, standards like PDF, 
emergent technologies like molecular computing; contract relationships with sovereign powers; and finally economic issues like insurance regulations.

Neuromedia will raise the level of concerns not only in the legal and ethical domains but far beyond into the way information is allowed to communicate with other information and what new forms emerge from those communications. What happens, for instance, if a network of neuromedia-based internet sites is continually exchanging data and generating new music, conceptual art, architectural designs, social models, or entertainment options? Who owns the results? Who preserves the cultural artifacts? What constitutes an artifact?

\section{NEUROMEDIA INFORMATION SCIENCE QUESTIONS}

Rather than a traditional conclusion, I would prefer to end this paper with questions. The answers to these questions may indicate a new approach to information science. The tools for digital discovery and preservation will change very rapidly. Digital technology as we now know it may only be a brief intermediary technology that is a step toward a more stable, potentially carbon-based form whose "materiality" may be vastly different than the silicon/plastic base with which we are now familiar.

1 What areas of current research in neuromedia will have the most effect on changing how we strategize digital management preservation technologies?

2 What are the prospects for synthetic cultural memory in this domain?

3 What methods and structures being created for current digital technologies will be most useful in neuromedia?

4 What is an authentic neuromedia digital record?
5 What are the prospects for digital continuity in this kind of information domain?

6 What kind of models based on the understanding of the nervous system will be useful for preserving digital information?

7 What is the ecology of neuromedia?

8 What sort of programming environments now being considered for non-silicon computing will be useful for asset management and preservation purposes?

9 What sort of organizations, institutions, and businesses will arise from neuromedia development?

10 How will the museum, design studio, and the science laboratory be joined?

11 What kind of products and services will be created that will impact long-term digital management and preservation?

12 Is neuromedia legal in terms of current models of intellectual property?

13 What is the time-line for neuromedia impact?

\section{Reference}

1 Emberly, E.G. and Kirczenow, G. (2003) "The smallest molecular switch," Physical Review Letters, Vol. 91, No. 18.

\section{Further reading}

Davis, B. and Kanarick, C. (eds) (2001) When Everything Learns, Razorfish PDF Publications, http://www.digitaleverything.com/ wheneverythinglearns2.pdf

Essex, D. (2002) "The Future of CPUs in Brief," Technology Review, MIT Enterprise, January 28.

MacLean, M. and Davis, B. (eds) (2000) Time and Bits: Managing Digital Continuity, J. Paul Getty Trust Publications, Los Angeles.

Quartz, S. R. and Sejnowski, T. J. (2002) Liars, Lovers, and Heroes: What the New Brain Science Reveals About How We Become Who We Are, W Morrow Publishing, Los Angeles.

Wilson, S. (2002) Information Arts: Intersections of Art, Science, and Technology, Leonardo Books, MIT Press, Michigan. 